\title{
A study on glycogen content of endometrial glands in infertile women
}

\author{
Karthik LR ${ }^{1}$, Raja Parthiban SR ${ }^{1}$, Savita ${ }^{1}$, Shruthi Neelakanth Shetageri ${ }^{1}$ \\ ${ }^{I}$ Department of Pathology, MVJ Medical college \& Research Hospital, Bengaluru, India
}

\section{Keywords: \\ Endometrium; Glycogen; Infertility;}

\begin{abstract}
Background: Infertility is a public health problem worldwide. One of the important factors involved in infertility is the poor quality of endometrium which leads to death of the ovum before and after implantation. Glycogen is known to be a direct source of nutrients for the early conceptus and its depletion may result in inadequate preparation of endometrium around the time of implantation and leading to infertility.
\end{abstract}

Materials and methods: This is a prospective study conducted at a tertiary care hospital for 2 years. The study included 75 cases of infertility (primary and secondary). Relevant data were collected from all the 75 biopsied infertile cases during the study period. Periodic acid Schiff stain was performed on all cases to detect the amount of glycogen in the endometrium. The findings were compiled, analyzed, and compared with other studies.

Results: Primary infertility accounted for $77.3 \%$ and Secondary infertility $22.7 \%$ of the 75 cases. On histology, anovulatory cycles accounted for $52 \%$ of cases. In the remaining cases, $38.7 \%$ showed secretory phase, $4 \%$ cases each showed luteal phase defect and hyperplasia, and $1.3 \%$ tubercular endometritis. Glycogen content of the endometrium was (1+) in $54.6 \%,(2+)$ in $9.3 \%,(3+)$ in $9.3 \%$ and (4+) in $26.8 \%$ in the infertility patients. Glycopenia was seen in $12 \%$ of the 75 cases studied.

Conclusions: Endometrial factors are important causes of infertility and depletion of glycogen, that can be corrected by hormonal therapy to improve the fertility potential needs to be evaluated in all cases of infertility.

\section{Correspondence:}

Dr. Shetageri Shruthi Neelakanth, $M D$

Associate Professor, Department of Pathology

MVJ Medical College \& Research Hospital, Bengaluru, India

ORCID ID: 0000-0002-6190-5255

Email:dr.shruthi.n.s@gmail.com

Received : July $2^{\text {nd }} 2020$; Accepted : September $21^{\text {st }} 2020$

Citation: Karthik LR, Parthiban SRR, Savita D, Shetageri SN. A study on glycogen content of endometrial glands in infertile women. J Pathol Nep. 2021;11(2): 1796-801. DOI10.3126/jpn. v11i2.35150

Copyright: This is an open-access article distributed under the terms of the Creative Commons Attribution 4.0 International License, which permits unrestricted use, distribution, and reproduction in any medium, provided the original author and source are credited.

\section{INTRODUCTION}

Infertility affects approximately $8 \%-10 \%$ of couples worldwide and India alone accounts for around $25 \%$ of cases. ${ }^{1}$ Infertility is a complex problem requiring a battery of tests to detect the defect. Endometrial biopsy not only is a simple, economical, and valuable method of determining ovulation but also provides information about any defect in the theaters-ovarian endocrine chain. ${ }^{2}$ One of the important factors involved in infertility is the poor quality of endometrium which leads to the death of the ovum before 
Table1: Age wise distribution of the cases

\begin{tabular}{lcc}
\hline Age group & Number of cases & Percentage(\%) \\
\hline $\mathbf{2 1}-\mathbf{2 5}$ & 26 & $34.6 \%$ \\
$\mathbf{2 6}-\mathbf{3 0}$ & 32 & $42.6 \%$ \\
$\mathbf{3 1}-\mathbf{3 5}$ & 15 & $20.0 \%$ \\
$\mathbf{3 6}-\mathbf{4 0}$ & 2 & $2.8 \%$ \\
\hline Total & 75 & $100 \%$ \\
\hline
\end{tabular}

and after implantation. Glycogen is known to be a direct source of nutrient for the early conceptus and its depletion may result in inadequate preparation of endometrium around the time of implantation, and hence causes infertility. ${ }^{3}$ Scarcity in the literature on the role of glycogen content in the endometrium as an etiological factor from rural south India prompted us to undertake this study to explore the role of glycogen content in the endometrium along with other factors like duration of infertility, the pattern of menstruation and other clinical features in causing infertility. ${ }^{4}$

\section{MATERIALS AND METHODS}

The present prospective study was conducted in a tertiary care hospital which caters to a rural population in and around Hoskote, for a period of 2 years from July 2018- July 2020. Ethical clearance was obtained from the institutional ethics committee for the study. The study included 75 cases biopsied to evaluate infertility (primary and secondary). Patients who failed to conceive after one year of unprotected coitus following marriage were investigated as cases of primary infertility and patients who failed to conceive after having prior conception were investigated as cases of secondary infertility. Detailed information of the clinical history of the menstrual cycle, last menstrual period, and obstetric history were obtained.

Inclusion criteria:

Endometrial biopsies from patients with primary or secondary infertility were included.

Exclusion criteria:

- Inadequate biopsies

- Cases previously worked up for infertility and on treatment.

Premenstrual endometrial tissues obtained from the obstetric and gynecology department were processed and subjected to routine processing. Haematoxylin and Eosin ( $\mathrm{H}$ and $\mathrm{E})$ and Periodic Acid-Schiff (PAS) stains were performed on all the cases and analyzed. Glycogen content was graded according to Arzac and Blanchet method as given below. ${ }^{5}$

$0=$ Negative reaction (no staining) $++=$ Very small granules; $++=$ Coarse granules; $+++=$ Small masses; $++++=$ Large masses

0 and $1+$ were taken as mild, ++ as moderate, +++ and ++++ were considered as high.The findings were compiled and analyzed in relation to the endometrial histology.

Table 2: Menstrual cycle: Distribution of normal and abnormal cycles

\begin{tabular}{|c|c|c|c|c|c|}
\hline \multirow{2}{*}{ Menstrual cycle } & & \multicolumn{2}{|c|}{ Primary Infertility } & \multicolumn{2}{|c|}{ Secondary Infertility } \\
\hline & & No. of cases & $\%$ & No. of cases & $\%$ \\
\hline Normal & & 35 & $60.4 \%$ & 12 & $70.6 \%$ \\
\hline \multirow[t]{4}{*}{ Abnormal } & Irregular & 13 & $22.4 \%$ & 02 & $11.8 \%$ \\
\hline & Oligomenorrhoea & 01 & $1.7 \%$ & 01 & $5.8 \%$ \\
\hline & Dysmennorhoea & 04 & $6.9 \%$ & 0 & 0 \\
\hline & Menorrhagia & 05 & $8.6 \%$ & 02 & $11.8 \%$ \\
\hline Total & & 58 & $100 \%$ & 17 & $100 \%$ \\
\hline
\end{tabular}

Table 3: Endometrial patterns in infertile cases

\begin{tabular}{|c|c|c|c|c|c|}
\hline \multirow{2}{*}{ Menstrual cycle } & \multicolumn{2}{|c|}{ Primary Infertility } & \multicolumn{2}{|c|}{ Secondary Infertility } & \multirow{2}{*}{ Total } \\
\hline & No. of cases & $\%$ & No. of cases & $\%$ & \\
\hline Proliferative (Anovulatory) & 32 & $55.2 \%$ & 7 & $41.2 \%$ & $39(52 \%)$ \\
\hline Secretory Phase & 22 & $37.9 \%$ & 7 & $41.2 \%$ & $29(38.7 \%)$ \\
\hline Luteal phase defect & 2 & $3.5 \%$ & 1 & $5.8 \%$ & $03(4 \%)$ \\
\hline Endometritis ( Tubercular) & 1 & $1.7 \%$ & 0 & - & $01(1.3 \%)$ \\
\hline $\begin{array}{l}\text { Hyperplasia (Disordered Proliferation \& } \\
\text { Simple Hyperplasia) }\end{array}$ & 1 & $1.7 \%$ & 2 & $11.8 \%$ & $03(4 \%)$ \\
\hline Total & 58 & $100 \%$ & 17 & $100 \%$ & $75(100 \%)$ \\
\hline
\end{tabular}


Table 4:Glycogen grading in the Infertile cases - PAS stain

\begin{tabular}{lccccccc}
\hline \multicolumn{2}{c}{$\begin{array}{c}\text { Glycogen content } \\
\text { \& Grade }\end{array}$} & Proliferative & Secretory & $\begin{array}{c}\text { Luteal Phase } \\
\text { defect }\end{array}$ & $\begin{array}{c}\text { TB } \\
\text { Endometritis }\end{array}$ & Hyperplasia & Total \\
\hline $\mathbf{0}$ (fig.1) & Mild & 25 & - & - & - & - & $25(33.3 \%)$ \\
+ (fig. 2) & & 14 & - & 1 & - & 1 & $16(21.3 \%)$ \\
++ (fig. 3) & Moderate & - & 03 & 2 & - & 2 & $07(9.3 \%)$ \\
\hline+++ (fig. 4) & & - & 06 & - & - & - & $07(9.3 \%)$ \\
++++ (fig. 5) & High & - & 20 & - & $\mathbf{1}$ & $\mathbf{3}$ & $\mathbf{3}(26.8 \%)$ \\
\hline Total & & $\mathbf{3 9}$ & $\mathbf{2 9}$ & $\mathbf{3}$ & & $\mathbf{7 5 ( 1 0 0 \% )}$ \\
\hline
\end{tabular}

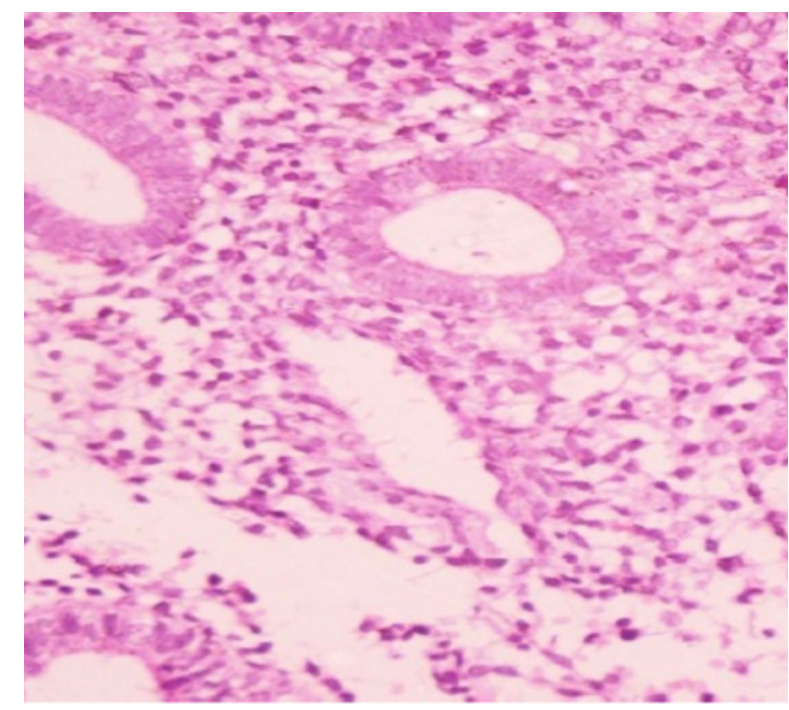

Figure 1: Grade 0: Proliferative phase showing negative reaction for $P A S \operatorname{stain}(40 x)$

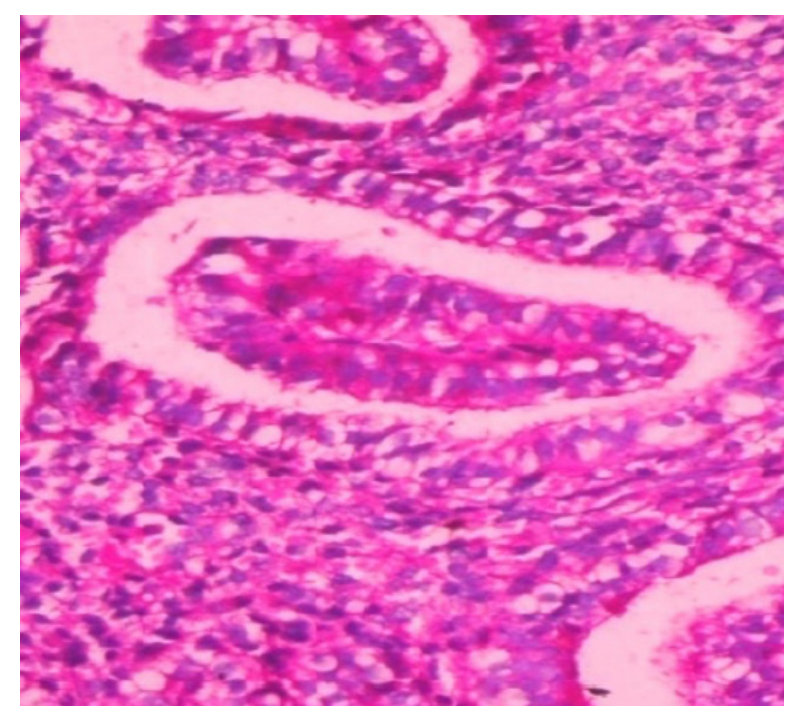

Figure 3: Grade ++: Secretory phase showing coarse granules on PAS stain (40x)

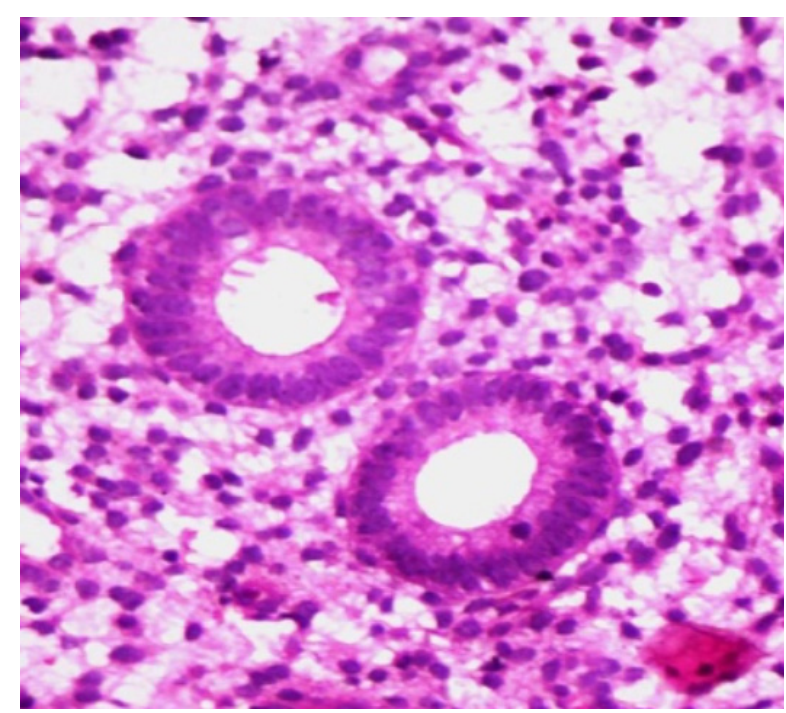

Figure 2: Grade +: Proliferative phase showing fine granules on PAS (40x)

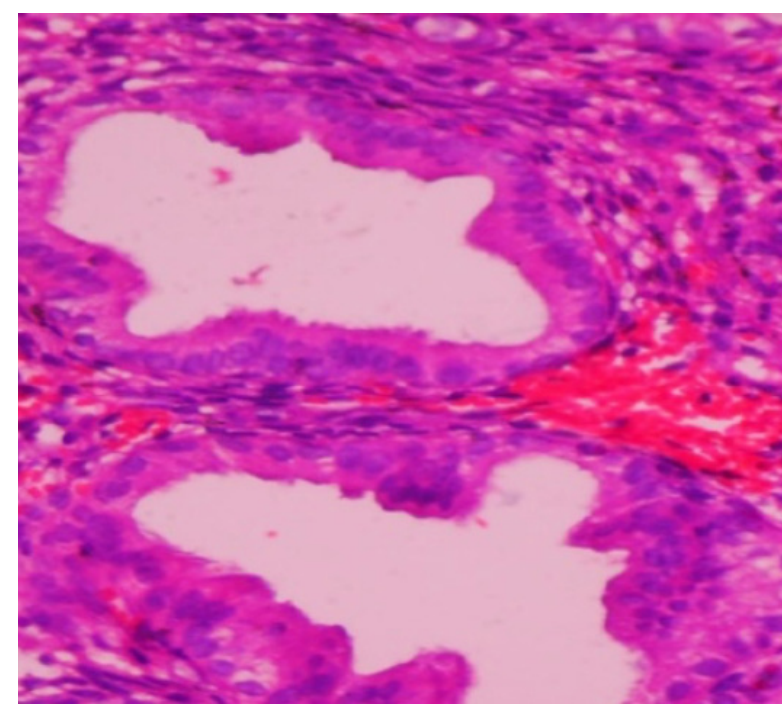

Figure 4: Grade +++ : Secretory phase showing small masses on PAS stain(40x) 


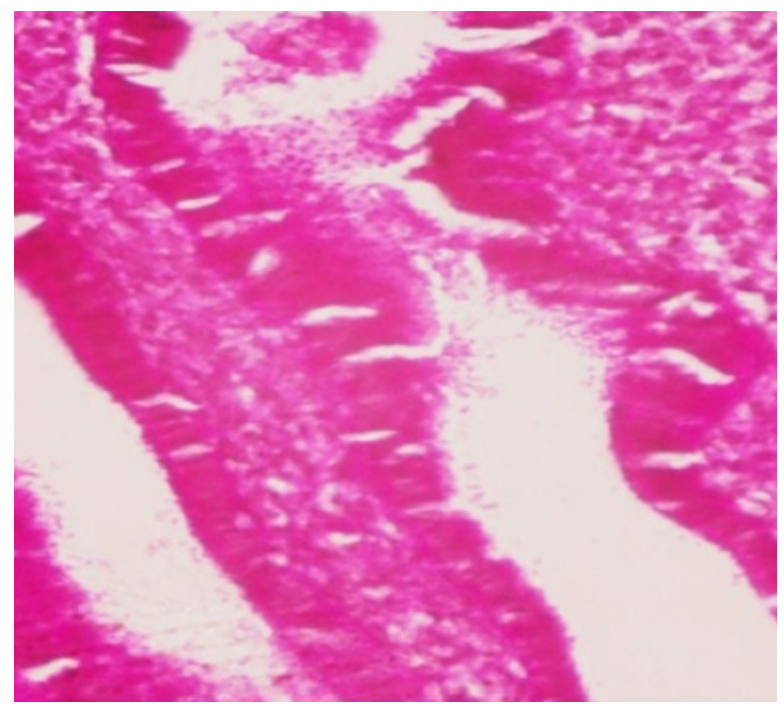

Figure 5: Grade ++++: Secretory phase showing large masses on PAS stain (100x)

All the data were collected in a proforma and entered into MS Excel sheets. Descriptive statistics like mean and percentage were used for the study. The findings obtained were analyzed and compared with similar studies in the literature.

\section{RESULTS}

Amongst 75 cases of infertility, $77.3 \%(n=58)$ of cases were of primary infertility and $22.7 \%(\mathrm{n}=17)$ of cases were of secondary infertility. The majority of patients were in the age group of 26-30 years(Table.1). The youngest patient was 21 years old and the oldest was 37 years.

Among 58 cases of primary infertility, 35 cases (60.4\%) had normal cycles and among 17 cases of secondary infertility, 12 cases $(70.6 \%)$ had normal cycles. In the cases with primary infertility, irregular cycles, menorrhagia, dysmenorrhea, and oligomenorrhea were the abnormalities encountered. In Secondary infertility too, irregular cycles, menorrhagia, and oligomenorrhea were noted as depicted in Table 2.

On histology, the most common finding was that of a proliferative pattern depicting anovulatory cycles. This was seen in $52 \%(n=39)$ of cases and was the most common pattern in both the primary and secondary infertility groups. A secretory pattern was observed in $38.7 \%$ of the 75 cases studied ( $\mathrm{n}=29$ ). This accounted for the next common finding in both primary and secondary infertility groups.

Luteal phase defect was seen in $4 \%$ of 75 cases studied. This accounted for $3.5 \%$ of primary and $5.8 \%$ of the secondary infertile groups. The hyperplasia group which included cases of both disordered proliferation and simple hyperplasia accounted for $4 \%$ of cases. This feature accounted for $1.7 \%$ of primary and $11.8 \%$ of secondary infertility cases. A single case of tubercular endometritis was encountered among the primary infertility cases. The findings are highlighted in Table 3

PAS staining and interpretation were done with appropriate controls for checking the adequacy of staining where in endometrium showed mild glycogen in $54.6 \%$, moderate in $9.3 \%$, heavy in $9.3 \%$, and intense in $26.8 \%$ of infertility patients.

\section{DISCUSSION}

In a rural hospital setup, where immunological and hormonal assay procedures are not easily available or affordable, endometrial biopsy is an important investigation for infertility. ${ }^{6}$ In our study, primary infertility was more common than secondary infertility i.e. 58 cases out of 75 cases $(77.3 \%)$ studied. Similar findings have been documented by Kauret $\mathrm{al}^{7}(77.14 \%)$ and Chelab et $\mathrm{al}^{8}$ (71.90\%).

The mean age of infertile women in our study was 29 yrs. This is comparable to studies by Kafeelet $\mathrm{al}^{9}$ ( 29 years, range of 21-37 years)and Ahmed $\mathrm{M}$ et al ${ }^{10}$ (33 years, range 23-43). Cases beyond this age become less in view of the loss of hope by the couples, 2nd marriage, or taking up adoption.

In spite of biopsies sampled in the premenstrual phase, proliferative /anovulatory pattern was the most common cause of infertility. Similar findings were also observed by Girishet $\mathrm{al}^{4}$ from Shimoga and Ikeme et $\mathrm{al}^{11}$ in Nigeria and Cheleb et $\mathrm{al}^{8}$ in Algeria. Other studies have found a secretory pattern to be more common which is an expected finding in a premenstrual biopsy. Polycystic Ovarian Disease (PCOD) which accounted for $12 \%$ of 75 cases explains the higher number of proliferative cases in our study.

Endometrial hyperplasia may be due to long-standing follicular persistence and a high level of unopposed estrogen. In the present study, endometrial hyperplasia accounted for $4 \%$ of the 75 cases. This is similar to the observations of Murmu et $\mathrm{al}^{6}(2.74 \%)$, Sabharwal et $\mathrm{al}^{12}$ $(2.66 \%)$, Shastrabudhe et $\mathrm{al}^{13}(4.4 \%)$, and Sharma et $\mathrm{al}^{14}(6.0 \%)$. Ahmed et $\mathrm{a}^{10}$ from Bangladesh who found a slightly higher incidence of $10.7 \%$, analyzed data from various countries and found this feature to be lower in India compared to Pakistan and Nigeria where incidence was as high as $14 \%$ and $20 \%$ respectively.

Luteal phase defect may be the cause of infertility in ovulatory cycles. The diagnosis of luteal phase defect is based on Jones criteria correlating between the last menstrual period and endometrial dating. In the present study, a luteal phase defect was noted in 3 of the 75 cases (4\%) studied. This is similar to that noted by Murmuet $\mathrm{al}^{6}$ who reported luteal phase defect in $8.2 \%$ of the 79 cases studied. This is the present study accounted for 1 of the 58 $(3.5 \%)$ cases with primary infertility and 2 of the $17(5.8 \%)$ cases with secondary infertility. In comparison, Murmuet 
al6 noted a higher proportion of secondary infertility cases with luteal phase defects $(16.7 \%)$. This could be due to the small sample size of secondary cases studied by them.

Tuberculous endometritis is still a major cause of infertility in developing countries and any woman with unexplained infertility should be investigated for tuberculosis. It accounted for $1.72 \%$ of our cases. Similar findings have been observed by Kafeelet al9 (0.8\%) and Ahmed M etal ${ }^{10}$ $(0.51 \%)$. In contrast, Punyashetty et $\mathrm{al}^{15}$ encountered a higher incidence of $3.9 \%$. Variations in socioeconomic status and education could be factors responsible for the variations.

In the present study, PAS stain was done on all 75 cases. Glycogen deficiency (mild) on PAS stain is indicated by Grade 0 and + , moderate amount of glycogen as ++ and high glycogen is indicated by +++ and ++++ . In our study glycogen depletion was seen in 41 cases $(54.6 \%)$ whereas it was $43.3 \%$ in a study done by Girish et $\mathrm{al}^{4}$ and $50 \%$ in a study done by Sharma et al. ${ }^{14}$ A moderate amount of glycogen was observed in $9.3 \%$ in our study whereas it was $26.7 \%$ in a study done by Girish et $\mathrm{al}^{4}$ and $16.7 \%$ in a study done by Sharma et al. ${ }^{14}$ High glycogen content was observed in $36 \%$ of cases in our study whereas it was $30 \%$ in a study done by Girish et al4 and $33.3 \%$ in a study done by Sharma et al. ${ }^{14}$

Genital tract glycogen is unique in that unlike muscular glycogen, it is unaffected by either carbohydrate intake or exercise. Maeyama et $\mathrm{a}^{16}$ assessed the urinary pregnanediol and found a high correlation between the function of corpus luteum and endometrial glycogen deposition. Hughes in 1967 reported that glycogen is present in the highest concentration around the 17 to 20 the day of the cycle. ${ }^{17}$ Interpretation of the relative finding mentioned above should be hence be done in the context of the phase of the cycle as done below, where the glycogen content is known to be low in proliferative and high in secretory phases.

All 39 cases that showed a proliferative phase on histology all had a glycogen content of $(0)$ and $(+)$ grade. Similar findings have been documented by Sharma et $\mathrm{al}^{14}$ and Girish et al. ${ }^{4}$ In the 29 cases showing secretory phase on histology a majority $(89.7 \%)$ of cases showed a grade $(+++)$ or $(++++)$ glycogen content. A similar finding of $92.3 \%$ was noticed by Sharma et al. ${ }^{14}$ Comparable results between the 3 studies can also be seen for luteal phase defect where all studies found reduced glycogen content of grade $(+)$ or $(++)$ and a slight predominance of grade $(++)$ levels.

Unlike our study, the other studies did not report the glycogen grade for cases of tubercular endometritis or hyperplasia. In the present study, the single case of tubercular endometritis showed a secretory pattern on histology and correspondingly a glycogen grade of $(+++)$. Endometrial hyperplasia, which is due to excess levels of estrogen can also modify the endometrial glycogen content.
In the present study, all the three cases studied had a lower glycogen content of $(+)$ or $(++)$.

Pradhan et $\mathrm{al}^{3}$ and Gupta et $\mathrm{a} \mathrm{l}^{18}$ have analyzed glycogen content in endometrial biopsies of infertile women in secretory phase and luteal phase defect where authors have reported a glycogen deficiency of $28.88 \%$ and $24.7 \%$ respectively. Similar findings have been noted in our study $(18.7 \%)$. However, the documentation of glycopenia in $12 \%$ of all 75 cases ( 3 cases of secretory, 3 cases of hyperplasia, and 3 cases of luteal phase defect) studied presents the true population who would receive hormonal therapy and thereby have an improved fertility potential. In the remaining cases which showed a proliferative pattern, an additional endometrial biopsy may be required on a followup to identify the true nature of the deficiency.

\section{CONCLUSION}

Our study highlights the importance of estimating glycogen deficiency in the endometrium in cases with infertility in a rural hospital setup. Depletion of glycogen has been documented by studies in the past including the present study. As this factor can be corrected by hormonal therapy and thereby improve the fertility potential; it may be worthwhile to assess this parameter routinely in all cases of unexplained infertility. It needs to be ascertained in the future whether glycopenia is a primary feature in the biopsy or secondary to the various histological changes noted in the endometrium.

\section{Conflict of interest: None}

\section{REFERENCES}

1. Pasi AL, Hanchate MS. Infertility and domestic violence: Cause, consequence and management in Indian scenario.Journal of Biomedical Research. 2011;22(2): 255-58. Website

2. Nandedkar SS, Patidar E, Gada DB, Malukani K, Munjal K, Varma A. Histomorphological patterns of endometrium in Infertility. The Journal of Obstetrics and Gynecology of India. 2015;65(5):328-34. Crossref

3. Pradhan SP, Dash A, Choudhury mS, Misra DP. A study on endometrial morphology and glycogen content in infertile women. Journal of Evidence Based Medicine and Healthcare. 2017;4(9):528531. $\underline{\text { Crossref }}$

4. Girish CJ, Naveen SK, Nagarajappa AH, Manjunath ML. A correlative study of endometrial glycogen content and other contributory factors on female fertility. International Journal of Biomedical and Advance Reserach.2012;3(1):30-5. Website

5. Arzac JP, Blanchet E. Alkaline phosphatase and glycogen in human endometrium. The Journal of Clinical Endocrinology. 1948;8(4):31524. $\underline{\text { Crossref }}$ 
6. Murmu S, Baitha B, Singh US. A Histopathological Study of Endometrium in Infertility. IOSR Journal of Dental and Medical Sciences 2017;16(1):56-60. $\underline{\text { Crossref }}$

7. Kaur P, Kaur A, Suri AK, Sidhu H. A two year histological study of endometrial biopsies in a teaching hospital in Northern India. Indian Journal of Pathology and Oncology. 2016;3(3):508-19. Crossref

8. Cheheb N, Tou A, Bekr FAA, Lebid M. The endometrial biopsy and hysteron-laparoscopy in evaluation of infertility. A prospective study in Algeria. Open Journal of Obstetrics and Gynecology. 2016;6:21018. Crossref

9. Kafeel S, Mushtaq H, Alam S. Endometrial histological findings in inferlite women. Journal of Islamabad Medical and Dental College. 2012(2); 61-64. Website

10. Ahmed M, Afroze N, Sabiha M. Histopathological Study of Endometrium in Infertility: Experience in A Tertiary Level Hospital. Bangladesh Institute of Research and Rehabilitation of Diabetes, Endocrine and Metaboloic disorders Medical Journal. 2018;8(2):1327. Crossref

11. Ikeme ACC, Fzegwui HU. Histological analysis of endometrial curettings performed for infertility in Nigeria. Journal of Obstetrics and Gynecology. 2004;24(8):914-15. $\underline{\text { Crossref }}$

12. Sabharwal BD, Sofat R, Chander K. Endometrial pattern and its glycogen content in case of infertility. Indian Journal of Obstetrics andGynecology. 1987;37:718-21. Crossref
13. Sahastrabudhe NS, Shinde S, Jadhav MV. Enometrium in infertility. Indian Journal of Obstetrics andGynecology. 2001;51:100-2 Website

14. Sharma V, Saxena V, Khatri SL. Histopathological study of endometrium in cases of infertility. International Journal of Clinical and Experimental Pathology. 2016;6:272-5. Crossref

15. Punyashetty KB, Patil AG, Andola SK, Katti TV, Vidisha A. A study of Endometrial etiological spectrum in causation of infertility in Gulburga, Karnataka. Indian Journal of Public Health Research \& Development. 2013;4(4):38-44. $\underline{\text { Crossref }}$

16. Maeyama M, Matsuo I, Nakahara K. Glycogen metabolism in vesicles of hydatidiform mole in vitro. Fertility and sterility. 1977;28(8):8515. $\underline{\text { Crossref }}$

17. Hughes EC. Relationship of glycogen to problems of sterility and ovular life. American Journal of Obstetrics and Gynecology. 1945;49(1):10-14. Crossref

18. Gupta A, Mathur SK, Gupta A. Correlation of histological dating and glycogen content by histochemical stain during various phases of menstrual cycle in primary infertility. Open Journal of Pathology. 2013;3(02):65. Crossref 